\title{
Current sensorless vector controlled induction motor drive
}

\author{
Vimlesh Verma \\ Department of Electrical Engineering, National Institute of Technology Patna, India
}

\begin{tabular}{l} 
Article Info \\
\hline Article history: \\
Received Dec 1, 2018 \\
Revised Feb 2, 2019 \\
Accepted Feb 7, 2019 \\
\hline
\end{tabular}

Keywords:

Current estimation Induction motor drive

Sensorless

Vector control

\begin{abstract}
This paper presents a current sensorless vector controlled induction motor drive with only speed sensor present in the system. The same performance as that of normal vector control drives (which uses two current and one speed sensor) is achieved with the proposed current sensorless drive. Such an approach is suitable for applications, where speed sensor cannot be eliminated. Thus, elimination of current sensor results in reduction of cost, increases reliability, reduced size and noise immunity. A new current estimation algorithm is proposed in this paper. The current estimation algorithm, estimates the current in two phase stationary reference frame. The proposed current estimation technique can also be used as a fault tolerant algorithm for normal vector controlled drives in case of current sensor failures. The performance of the current sensorless drive using the proposed current estimation technique is verified through MATLAB/SIMULINK. Extensive simulation results are presented to confirm the effectiveness of the algorithm. The algorithm is also experimentally validated with the laboratory developed prototype and the results are presented. The prototype is built around a dSPACE 1104 controller board.
\end{abstract}

Copyright $\odot 2019$ Institute of Advanced Engineering and Science. All rights reserved.

\section{Corresponding Author:}

Vimlesh Verma,

Department of Electrical Engineering,

National Institute of Technology Patna, Patna-800005, India.

Email: vimlesh.verma@nitp.ac.in

\section{INTRODUCTION}

Induction machines are the work horse of the present day industry due to their simplicity and rugged construction. Control of these machines is quite complex due to coupling between flux and torque. Thus, speed control of induction motor drive can be divided into two categories, i.e., scalar control (volt/Hertz) and vector control. Scalar control induction motor drives are simple to implement, reliable and cost effective. In scalar control, a dc voltage sensor and/or a speed sensor is needed. However, the dynamic performance of such drives is sluggish when speed/torque change occurs. Thus vector control is adopted in applications which need good dynamic performance and precise speed/position control. However, the control structure of vector control drives is complex and expensive compared to scalar control as the number of sensors increases (i.e., two current and one speed sensor). In the past several research works have been done related to speed sensorless strategies, but little work has been done related to current sensorless drives. The speed sensorless drive needs two current sensors to estimate the speed and rotor position. The current sensorless drive needs speed/position sensor to achieve the same performance. Generally, drives based on volt/Hertz, uses a speed/position sensor. For this kind of drives no current sensor is adopted for the measurement of three phase current. But the drawback with this kind of approach is already discussed.

Therefore, the main motivation behind this work is to achieve vector control with the existing speed/position sensor based volt/Hertz drives. As, already discussed, vector controlled drives need two current sensors for its implementation. Hence, these currents will be estimated in two phase stationary reference frame in case of drives where speed/position sensor is available to achieve vector control. Also, there are applications (like positioning), where the speed/position sensor cannot be removed to assure 
precision and reliability. Proposed algorithm can also be used in the applications where, automatic reconfiguration of controller is done from sensorless vector control (when a speed/position sensor fails) to volt/Hertz control (when phase current sensors fail). For this application (i.e., when both the current sensors fail and speed sensor is healthy in case of vector control drive) instead of shifting the drive from vector control to volt/Hertz, the drive can still be made to operate as an vector control drive, with the help of proposed current estimation technique. This paper presents a new current estimation technique for such kind of applications. Several methods for estimation of current are presented in literature. Green et al. [1] proposed the reconstruction of phase currents from the DC-link current signal in 1989. Research works in [2-3] introduced the modifications to the modulation algorithm in order to guarantee the reliability of the measurements from the DC-link current sensors. Motor phase current was also estimated by using predictioncorrection algorithms, thus introducing additional computational burden to the drive system [4-5]. In [6] a space vector modulation pattern modification (SVM-PM) is proposed that produces lower current harmonic content. The SVM-PM, required to reconstruct the phase currents, increments the power losses, the audible noise and the high-frequency content in voltages and current [7]. The inverter output voltage is reduced by the SVM-PM in the over modulation operating mode [8]. The negative effects of SVM-PM is overcome in [9] with the help of a state observer working along with SVM-PM. In [10], direct torque control (DTC) scheme for IM drives based on single current sensor placed in the inverter DC-link is proposed. Here the phase current is first predicted by means of suitable motor model and then adjusted with the help of sensed DC-link current. The drawback is the additional computational burden.

In [11], a current sensor arrangement for the acquisition of true instantaneous phase current from the DC-link signal, together with the short-circuit and ground fault protections is implemented with only one current sensor. The DC-link sensed current remains sensitive to narrow-pulse problems, and further deteriorates if the cable capacitance causes spurious oscillations in the DC-link waveform. This problem is solved in [12], where the control algorithm is based on the calculations of instantaneous active and reactive power from the DC-link current and PWM pattern. Three individual observers (one for each phase) are used in [13] to estimate the phase current from voltage and flux signals. This method is dependent on the variation of stator resistance. In all the above methods, current sensor is placed in the DC-link. It is noticed that all of the aforesaid methods based on DC-link current measurement require the information of machine model and switching states of the inverter. In [14-22], current sensorless algorithms are presented. All these methods are based on accurate machine models, which weaken the robustness of the corresponding drive. In [23], a hybrid PWM technique is used to reconstruct the current, reduce the current distortion and decrease the THD of inverter. The proposed method combines SVM and PWM techniques to reduce the un-measurable active voltage area but, increases the algorithm complexity. Further modifications are made in the PWM techniques to eliminate the problems related to traditional DC-link sensing [24]. In [24], the switching loss is less and there is a reduction in the dc current ripple. However, it results in increased THD at lower modulation index. To implement the current estimation method in [25], inverter needs to be constructed with six individual IGBT's. Hence, the method will fail if, each leg of the inverter is made using dual pack IGBT modules or all the six IGBT's come in a single pack. In [26] and [27], a new method to estimate the phase currents using single current sensor is presented for a DMC fed AC motors. Note that the proposed method depends on specific location of the current sensor. Therefore, implementation of the proposed method needs a small change in the converter connection to place the current sensor.

In this paper, a current sensorless based vector controlled induction motor drive is presented. Here, speed sensor is used to achieve vector control without using current sensors. The currents are estimated in two phase stationary reference frame, with the help of reference value of $d$-axis stator current. The reference value of $\mathrm{d}$-axis current is obtained from machine ratings. The proposed algorithm uses two simple equations for its estimation. The algorithm does not require any extra hardware for its implementation and thus makes it suitable for retrofit applications. The paper is divided into six sections. Section-I deals with literature review on various current estimation methods and current sensorless based drives. The proposed current estimation algorithm is present in section-II. Simulation results are available in section-III. Section-IV deals with the hardware setup description and corresponding experimental results are available in section-V. Section-VI concludes the work.

\section{PROPOSED CURRENT ESTIMATION ALGORITHM}

The proposed current estimation algorithm is shown in Figure 1. Here the currents are estimated in two phase stationary reference frame. Initially, the rated value of flux is calculated with the help of reference value of d-axis stator current. The obtained value of rotor flux is then used, to calculate the flux in stationary reference frame with the help of vector rotator. Also, the equation of rotor flux in stationary reference frame depends on stator currents and stator voltages. Reference value of stator voltage is used in this equation. 
Thus, the unknown quantity present in equation is the stator current. Hence, it can be estimated. The corresponding equations are discussed later. Overall block diagram of the drive is presented in Figure 2.

\subsection{Theoretical Development:}

Rotor flux in stationary (stator) reference frame is given as (1-2):

$$
\begin{aligned}
& \psi_{r \alpha}=\psi_{r} \cos \rho_{m s} \\
& \psi_{r \beta}=\psi_{r} \sin \rho_{m s}
\end{aligned}
$$

Where $\psi_{r}=L_{m} * i_{s d}^{*}$ and $\rho_{m s}$ is the position of rotor flux with respect to stator axis. $i_{s d}^{*}$ is the reference value of $\mathrm{d}$ axis current in rotating reference frame. Here $L_{m}$ and $i_{s d}^{*}$ are known. Thus $\psi_{r}$ is also known. Rotor flux in stationary reference frame can be expressed as (3-4):

$$
\begin{aligned}
& \psi_{r \beta}=\frac{L_{r}}{L_{m}}\left(\psi_{s \beta}-\sigma L_{s} i_{s \beta}\right) \\
& \psi_{r \alpha}=\frac{L_{r}}{L_{m}}\left(\psi_{s \alpha}-\sigma L_{s} i_{s \alpha}\right)
\end{aligned}
$$

where, $\psi_{s \beta}$ and $\psi_{s \alpha}$ are given as (5-6)

$$
\begin{aligned}
& \psi_{s \beta}=\int\left(v_{s \beta}^{*}-R_{s} i_{s \beta}\right) d t \\
& \psi_{s \alpha}=\int\left(v_{s \alpha}^{*}-R_{s} i_{s \alpha}\right) d t \\
& \text { Also, } \sigma=1-\frac{L_{m}^{2}}{L_{r} L_{s}}
\end{aligned}
$$

Substituting (2) and (5) in (3) and solving for $i_{s \beta}$ we get (7)

$$
\hat{i}_{s \beta}=\frac{1}{\sigma L_{s}}\left[\int\left(v_{s \beta}^{*}-R_{s} \hat{i}_{s \beta}\right) d t-\frac{L_{m}}{L_{r}} \psi_{r \beta}\right]
$$

Similarly, $i_{s \alpha}$ is (8) estimated by substituting (1) and (6) in (4).

$$
\hat{i}_{s \alpha}=\frac{1}{\sigma L_{s}}\left[\int\left(v_{s \alpha}^{*}-R_{s} \hat{i}_{s \alpha}\right) d t-\frac{L_{m}}{L_{r}} \psi_{r \alpha}\right]
$$

In Figure 1, $K 1=\frac{1}{\sigma L_{s}}$ and $K 2=\frac{1}{\sigma L_{s}} * \frac{L_{m}}{L_{r}}$. 


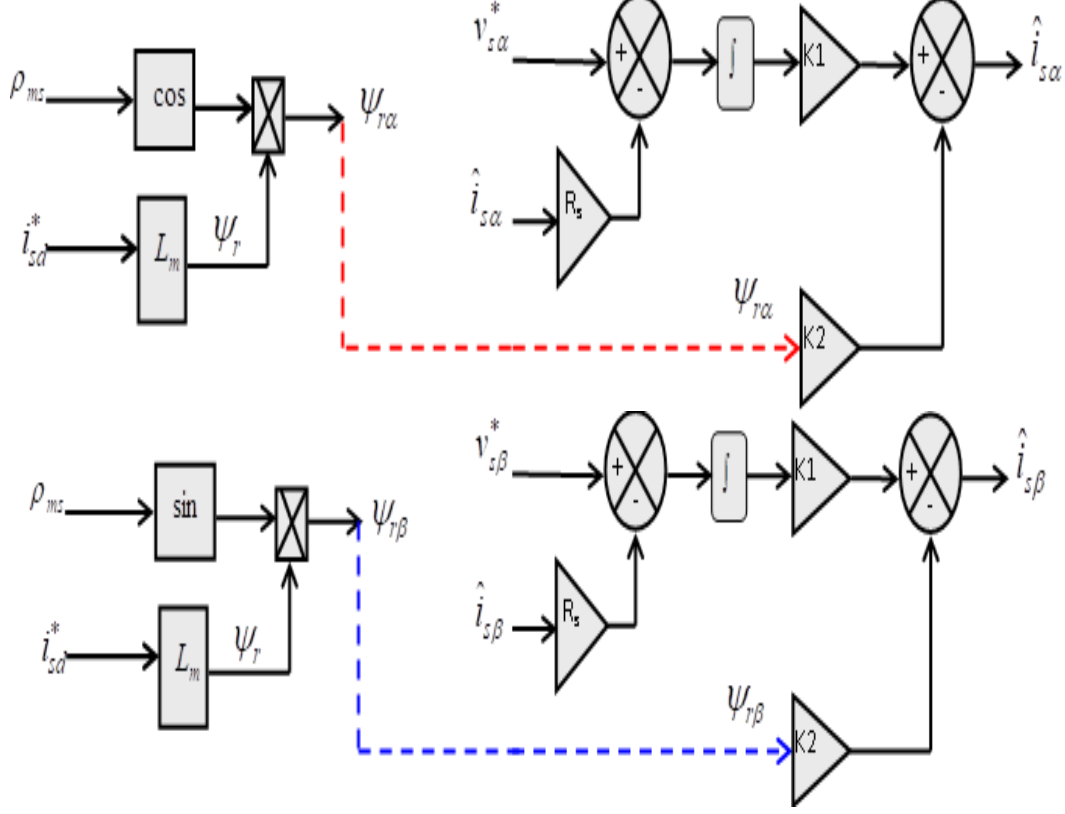

Figure 1. Proposed current estimation technique

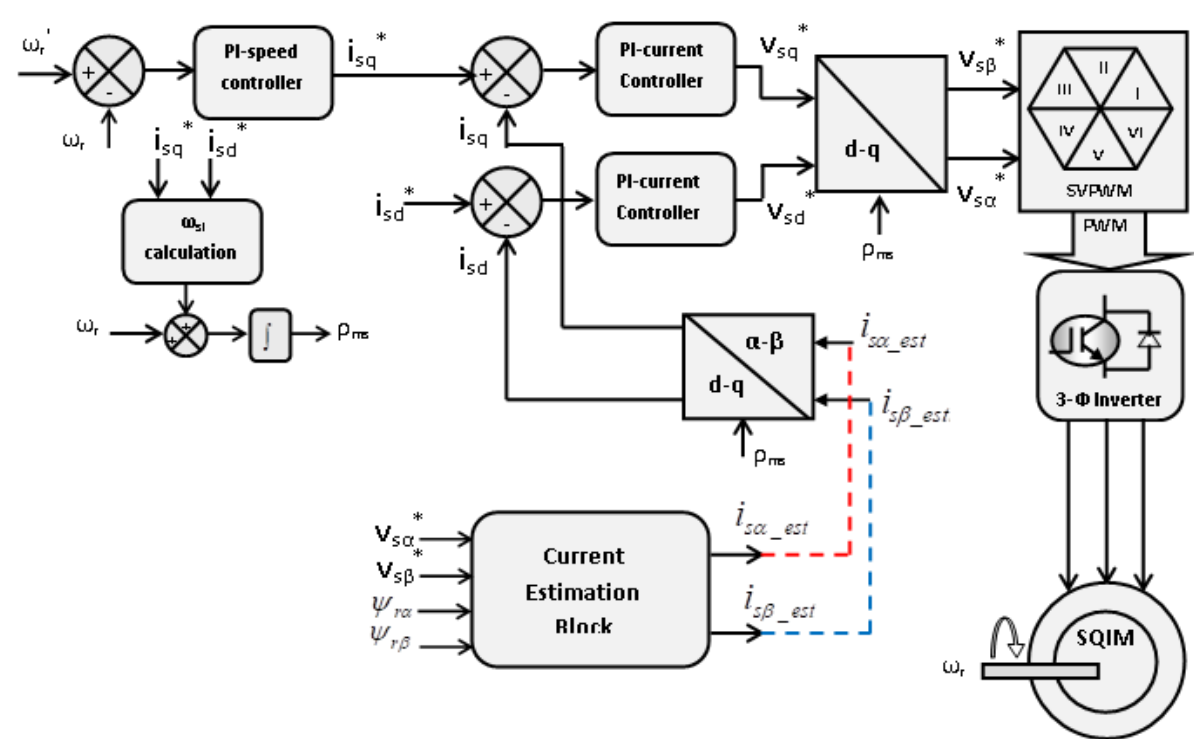

Figure 2. Schematic block diagram of IM drive with proposed current estimation technique

\section{SIMULATION RESULTS}

The proposed current sensorless method has been simulated using MATLAB/SIMULINK. This section presents some of the simulation results corresponding to the proposed algorithm. The machine parameters are available in Table 1 as shown in APPENDIX.

\subsection{Step change in rotor speed}

The performance of the induction motor for step change in rotor speed is presented. A step change in speed of $20 \mathrm{rad} / \mathrm{s}$ is applied at $5 \mathrm{~s}$ from $0 \mathrm{rad} / \mathrm{s}$. The corresponding results are shown in Figure 3. Figure 3(a) shows how the actual $\left(\omega_{r}\right)$ rotor speed follows the reference $\left(\omega_{r}^{*}\right)$ speed. The $\mathrm{d}$ and $\mathrm{q}$ axis rotor flux components are presented in Figure 3(b), which reflects flux orientation. The flux and torque components of the currents are shown in Figure 3(c) and Figure 3(d). The actual current (using two current sensors) and estimated $\alpha$ - and $\beta$-axis currents are presented in Figure 3(e) and Figure 3(f). It is observed that estimated current follows the actual with negligible error. 


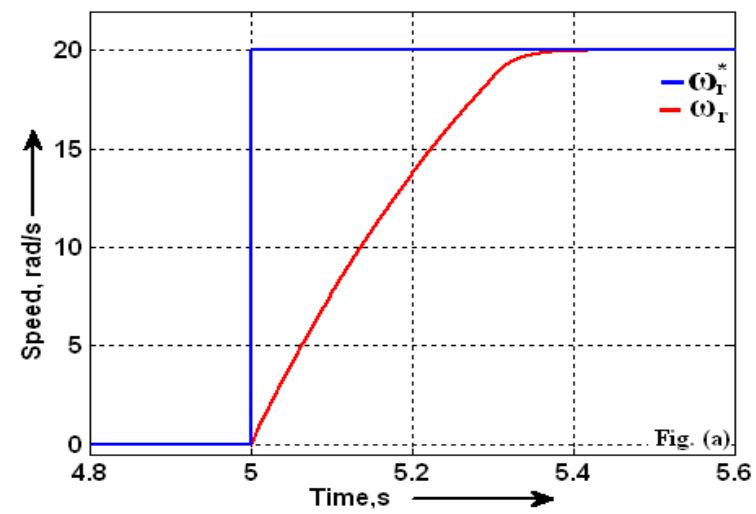

(a)

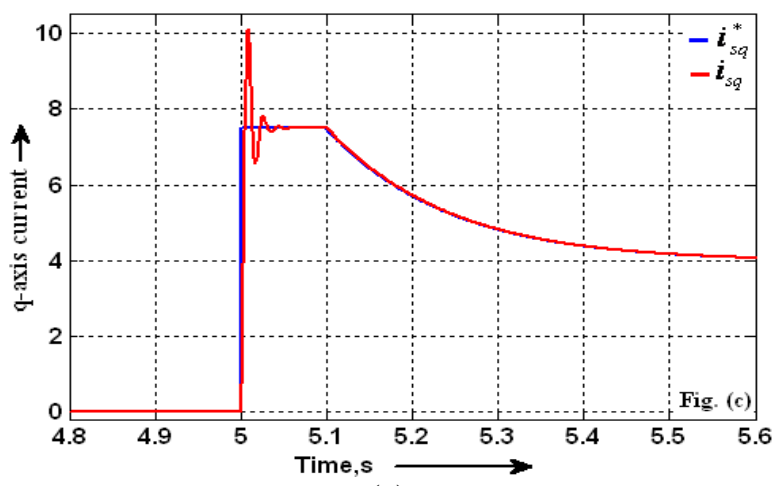

(c)

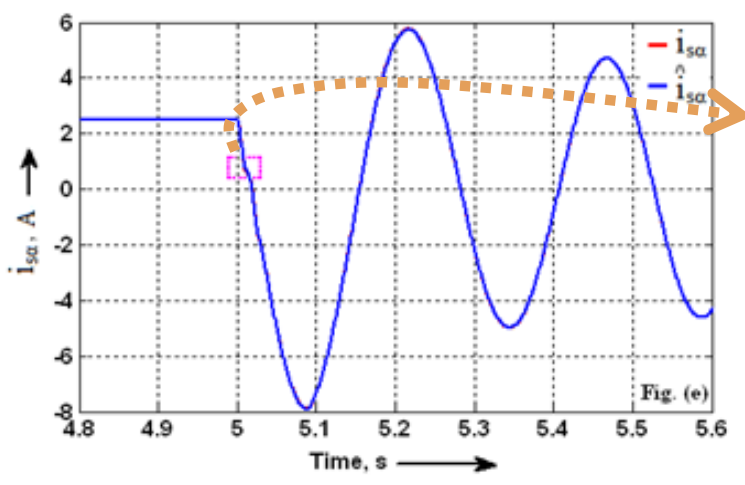

(e)

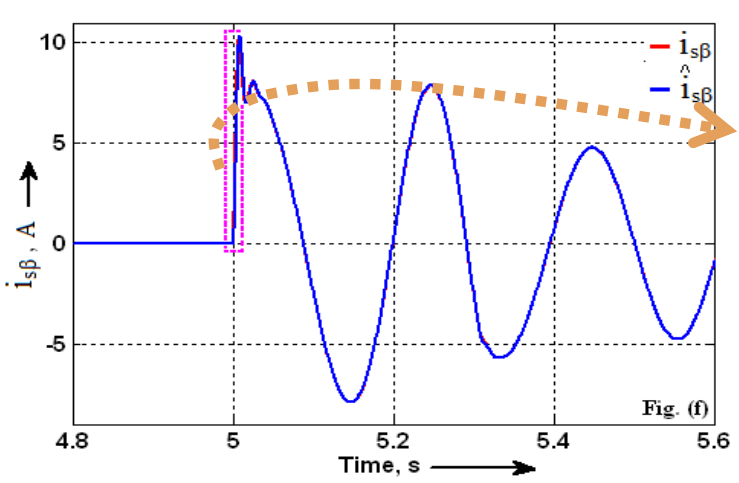

(f)

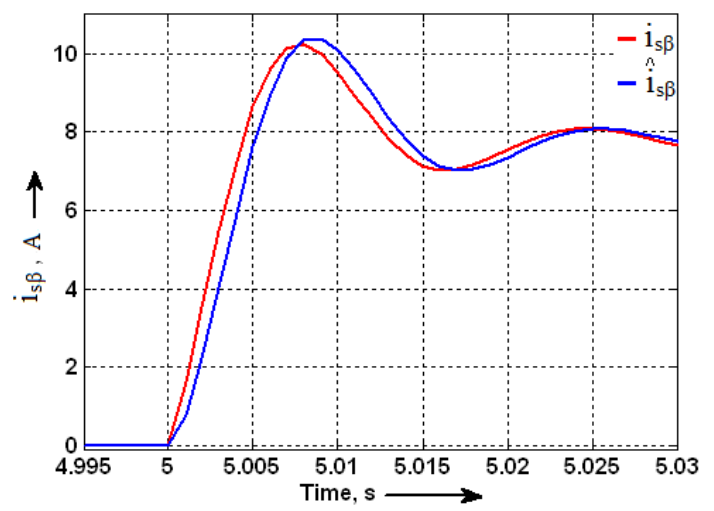

(d)

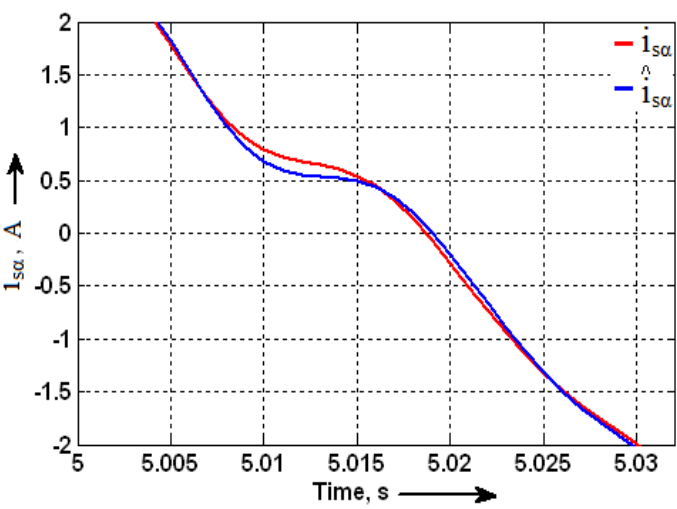

(b)
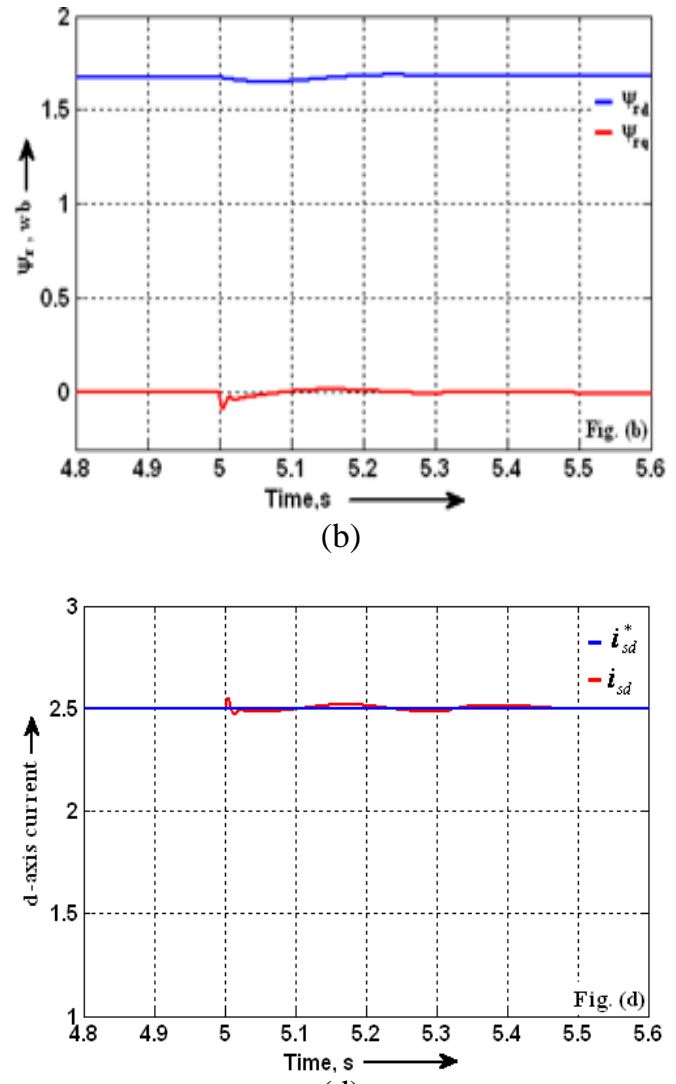


\subsection{Speed Reversal}

The proposed algorithm is also tested for forward and reverse motoring by applying a square wave speed command. The reference speed $\left(\omega_{r}^{*}\right)$ is changed from $+20 \mathrm{rad} / \mathrm{s}$ to $-20 \mathrm{rad} / \mathrm{s}$ at $17.5 \mathrm{~s}$. The corresponding actual speed $\left(\omega_{r}\right)$ is shown in Figure $4(\mathrm{a})$. The flux orientation is not disturbed as can be seen in Figure 4(b). The reference and actual values of torque and flux currents are shown in Figure 4(c) and Figure 4(d). Performance of the current estimator is presented in Figure 4(e) and Figure 4(f), which reveals the error between actual and estimated current is negligibly small.

\subsection{Ramp Response}

The performance of drive under slow zero crossing is observed when reference speed is changed from positive to negative in the form of a ramp. The reference and actual speed, rotor flux component, flux and torque component of stator current, actual and estimated values of $\alpha$ - and $\beta$-axis current are presented in Figure 5.

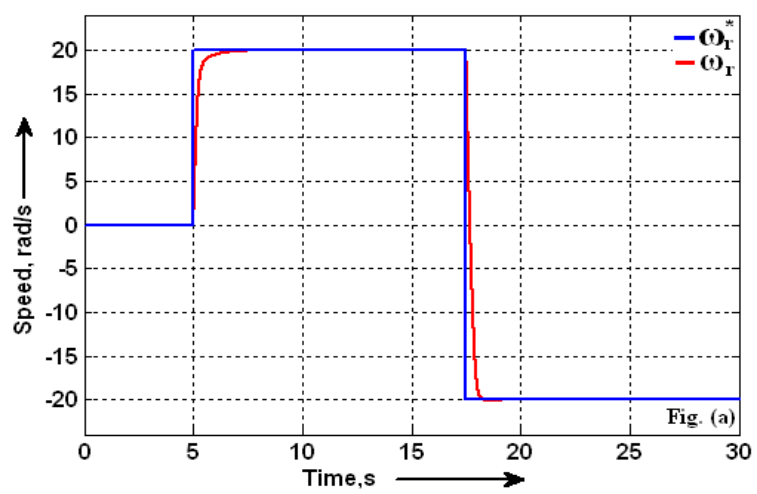

(a)

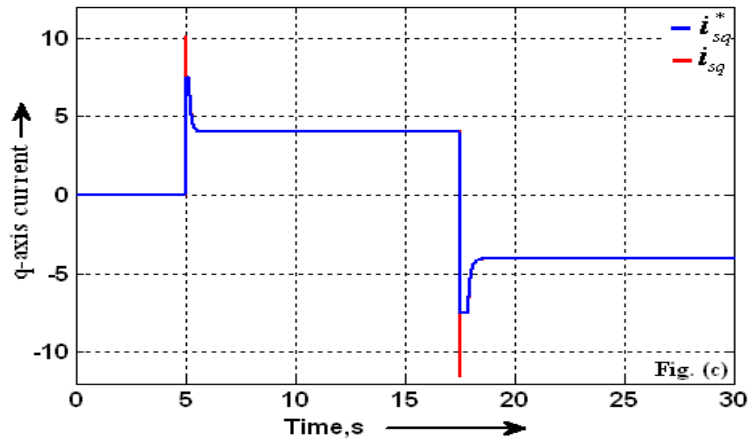

(c)

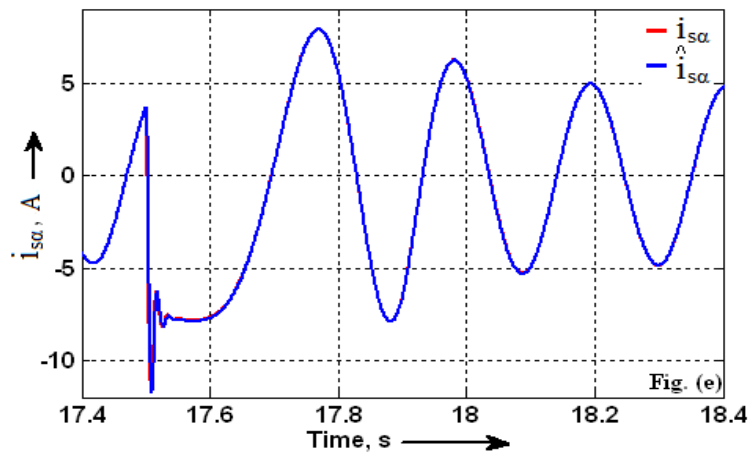

(e)

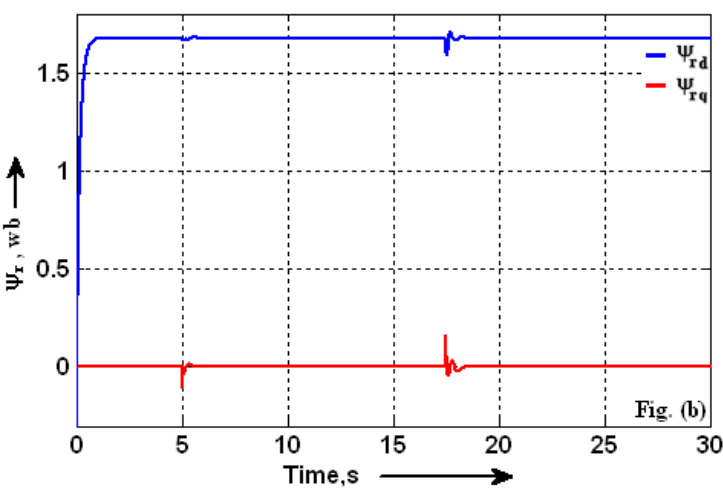

(b)

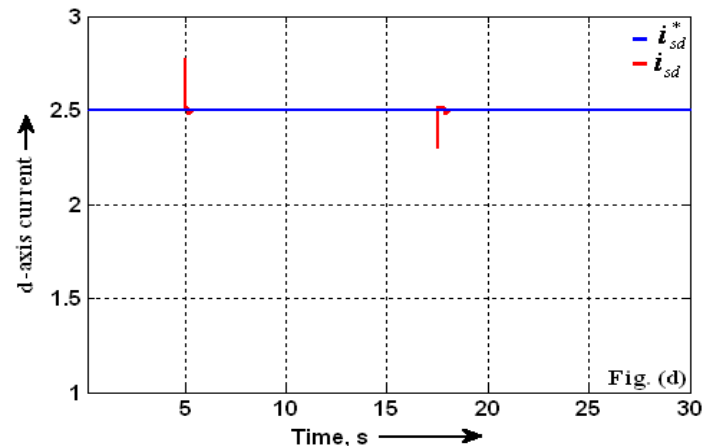

(d)

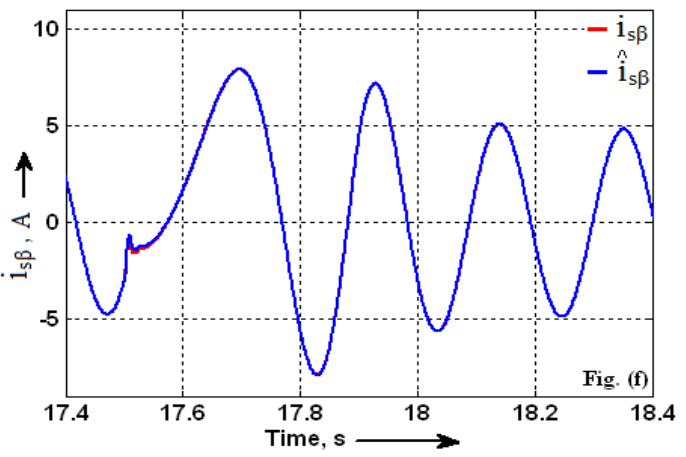

(f)

Figure 4. Simulation results under speed reversal $\left(T_{L}=0.5 \mathrm{pu}\right.$ at $\left.20 \mathrm{rad} / \mathrm{s}\right)(\mathrm{a})$ reference and actual rotor speed (b) rotor flux (c) q-axis current (d) d-axis current (e) $\alpha$-axis current (f) $\beta$-axis current 


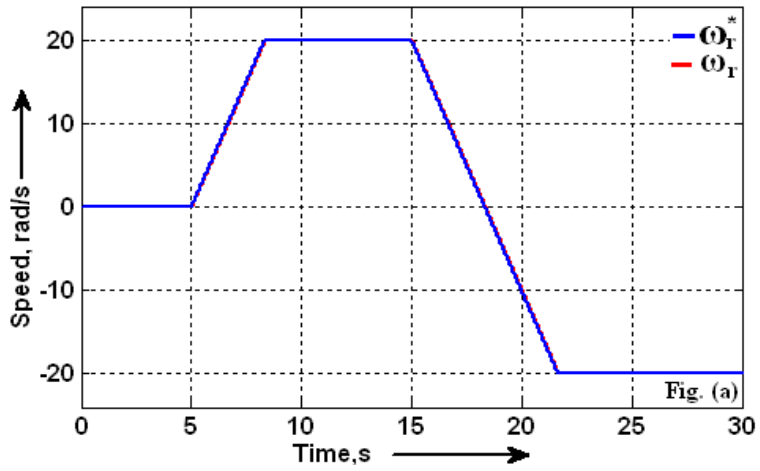

(a)

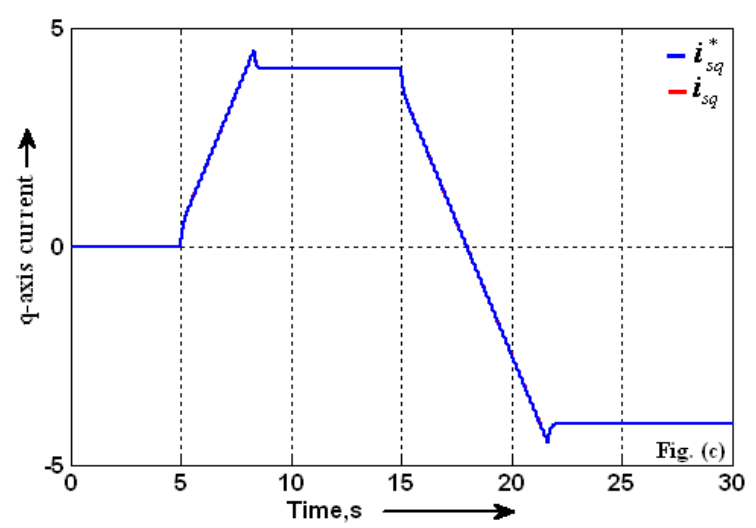

(c)

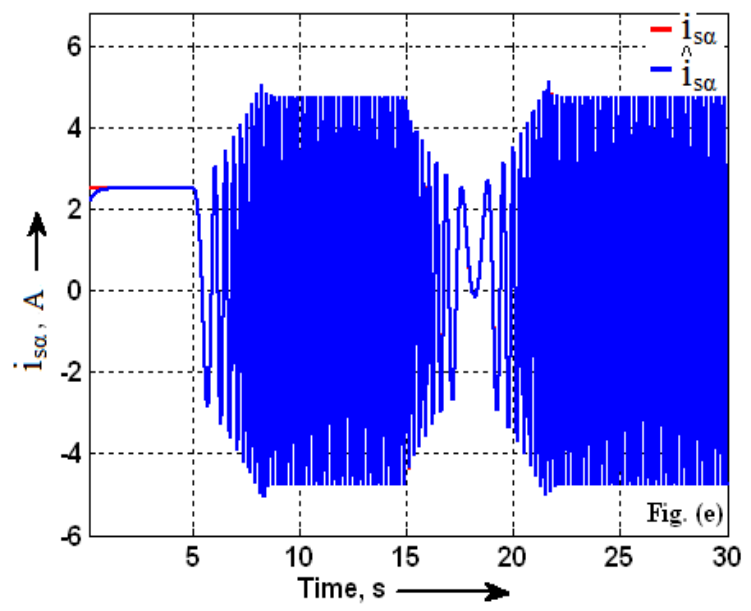

(e)

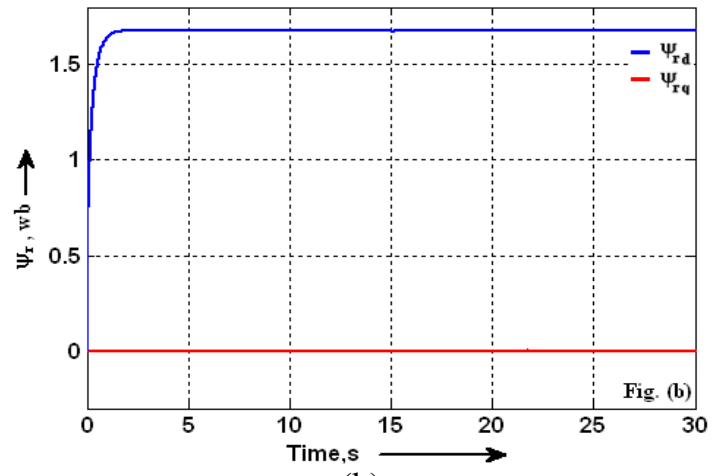

(b)

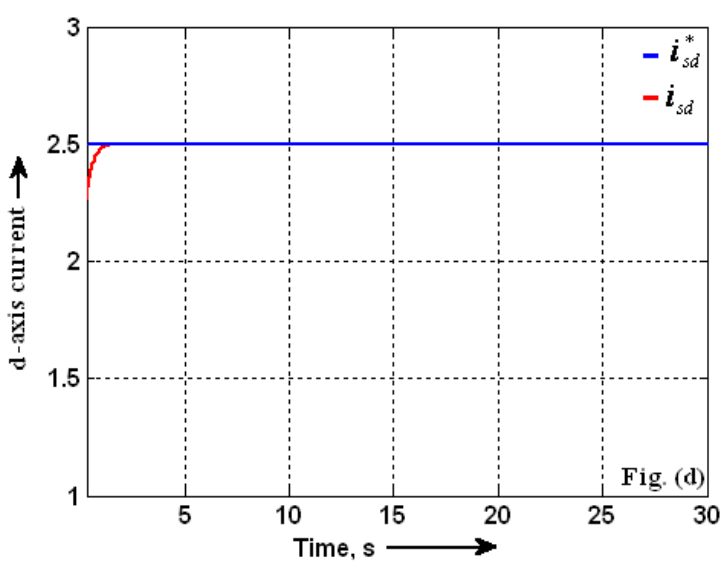

(d)

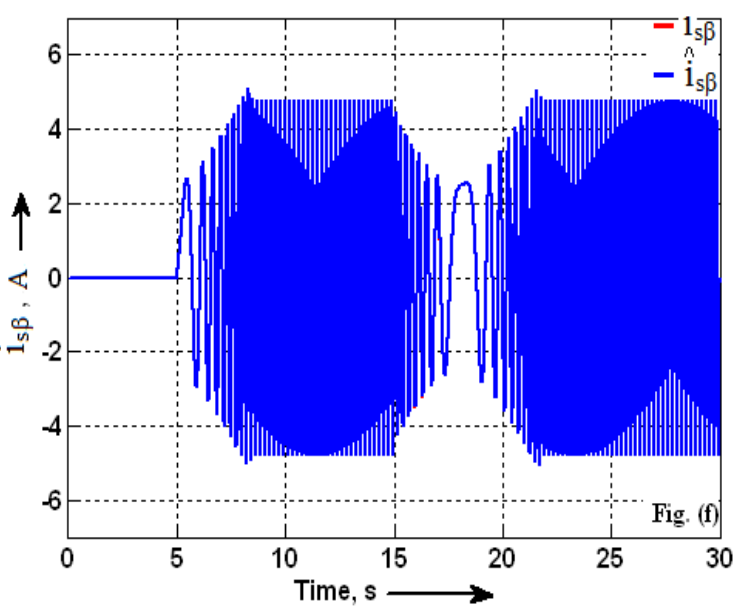

(f)

Figure 5. Simulation results under ramp speed command ( $T L=0.5 p u)$ (a) reference and actual rotor speed (b) rotor flux (c) q-axis current (d) d-axis current (e) $\alpha$-axis current (f) $\beta$-axis current

\subsection{Performance under sinusoidal speed command}

The performance of the sensorless drive under sinusoidal speed command is observed in Figure 6. Reference versus actual speed is shown Figure 6(a). It is observed that the actual speed tracks the reference one with good accuracy. From Figure 6(b), it is noticed that flux orientation is maintained throughout the operation. The $d$ and $q$ axis stator currents are shown in Figure 6(c) and Figure 6(d).

\subsection{Performance under triangular speed command}

The performance of drive under triangular speed command is observed in Figure 7. It is observed that the actual speed tracks the reference one with good accuracy as shown in Figure 7(a). From Figure 7(b), 
it is noticed that flux orientation is maintained throughout the operation. The d-and q-axis stator currents are shown in Figure 7(c) and Figure 7(d).

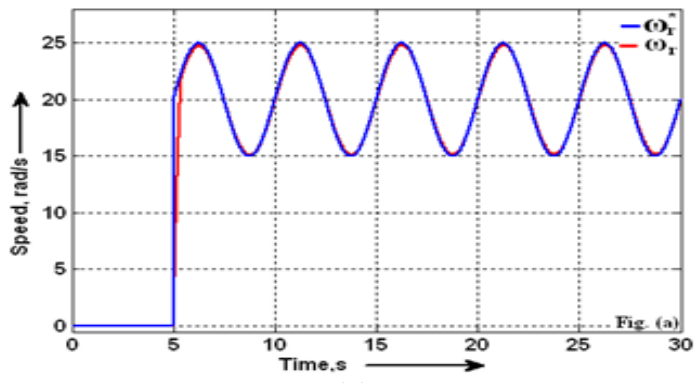

(a)

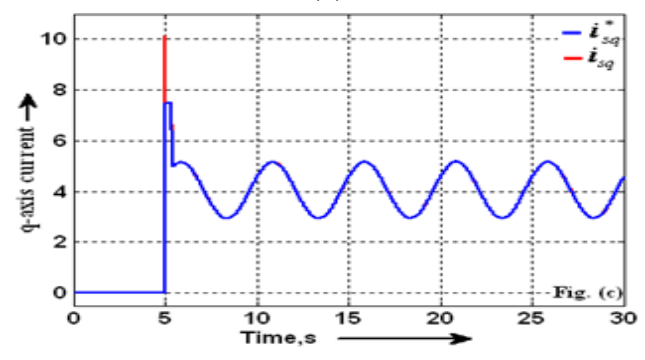

(c)

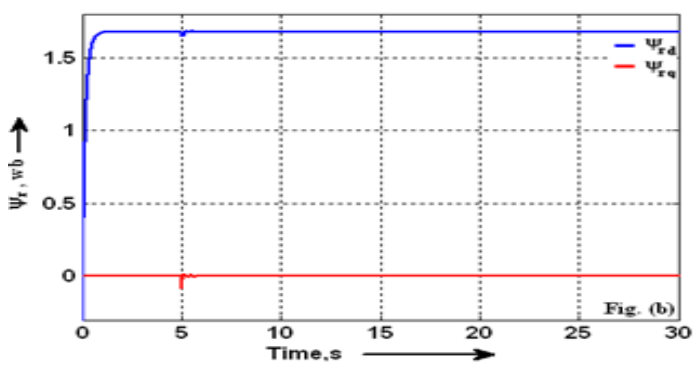

(b)

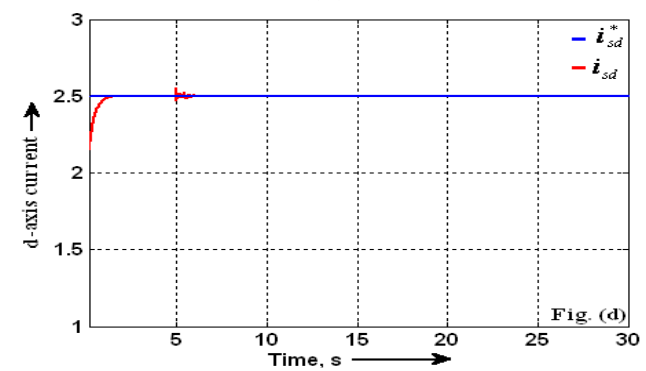

(d)

Figure 6. Simulation results under sinusoidal speed command $\left(\mathrm{T}_{\mathrm{L}}=0.5 \mathrm{pu}\right)$ (a) reference and actual rotor speed (b) rotor flux (c) q-axis current (d) d-axis current

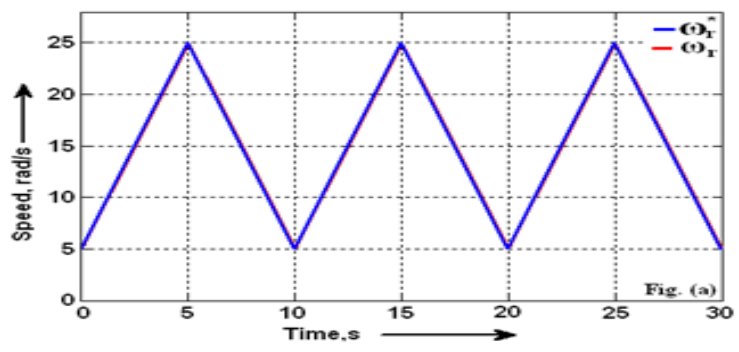

(a)

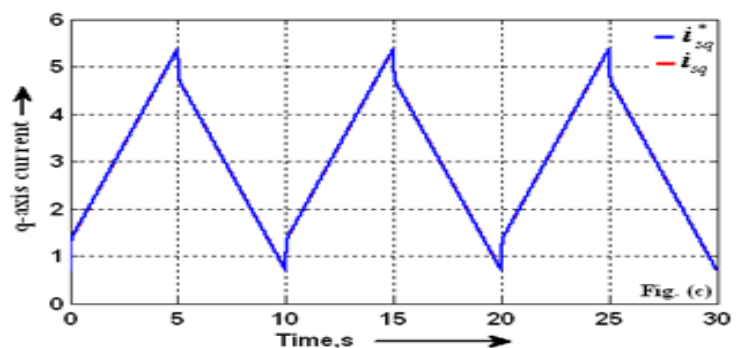

(c)

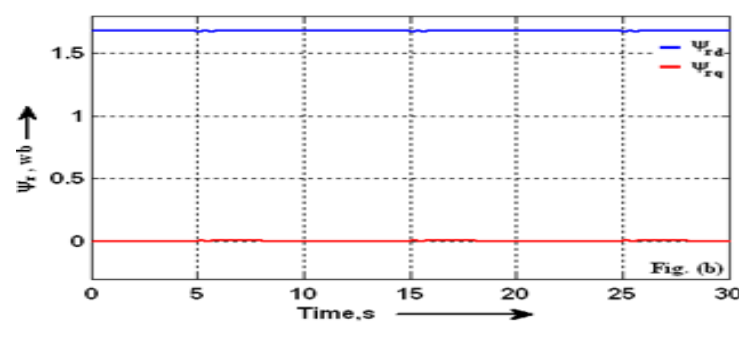

(b)

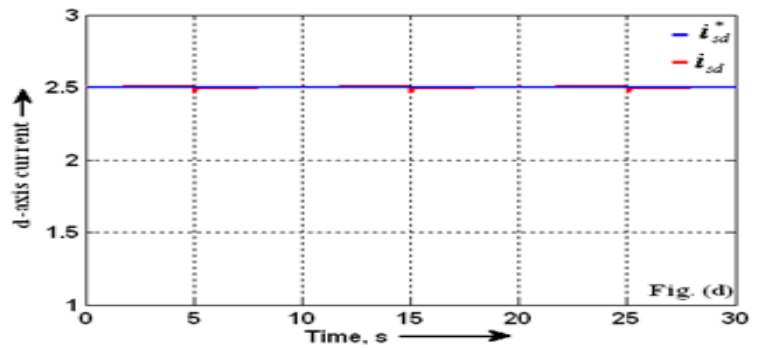

(d)

Figure 7. Simulation results under triangular speed command $\left(T_{L}=0.5 p u\right)$ (a) reference and actual rotor speed (b) rotor flux (c) q-axis current (d) d-axis current

\subsection{Motoring and regenerating mode of operation}

Performance of the drive in all the four quadrant of operation is shown in Figure 8. Here the reference speed is changed from $10 \mathrm{rad} / \mathrm{s}$ to $-10 \mathrm{rad} / \mathrm{s}$. The load torque is also changed from $+5 \mathrm{~N}-\mathrm{m}$ to $-5 \mathrm{~N}-\mathrm{m}$ and is again brought back to $+5 \mathrm{~N}-\mathrm{m}$. At $15 \mathrm{~s}$ load torque is made negative, but speed is still positive. This indicates forward braking operation of drive as indicated in Figure 8(a). Similarly other quadrant 
operations are also shown in Figure 8(a). Orientation of flux in all the four quadrant of operation is shown in Figure 8(b). The flux and torque components of currents are shown in Figure 8(c) and Figure 8(d).

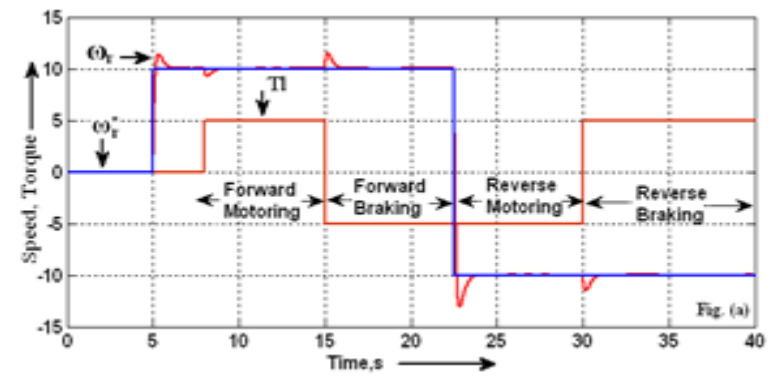

(a)

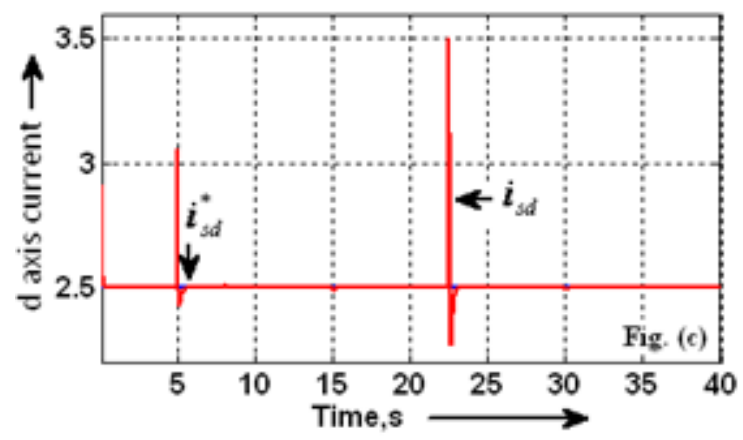

(c)

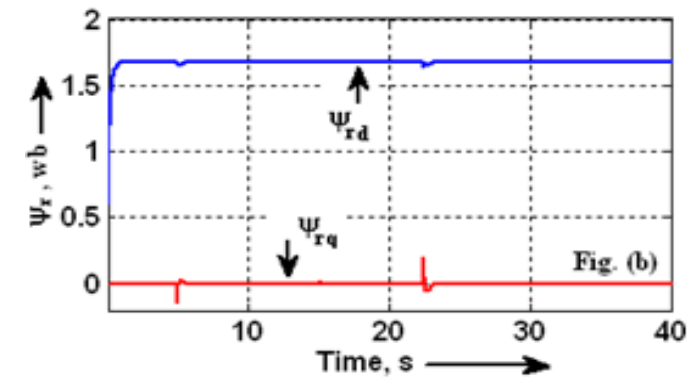

(b)

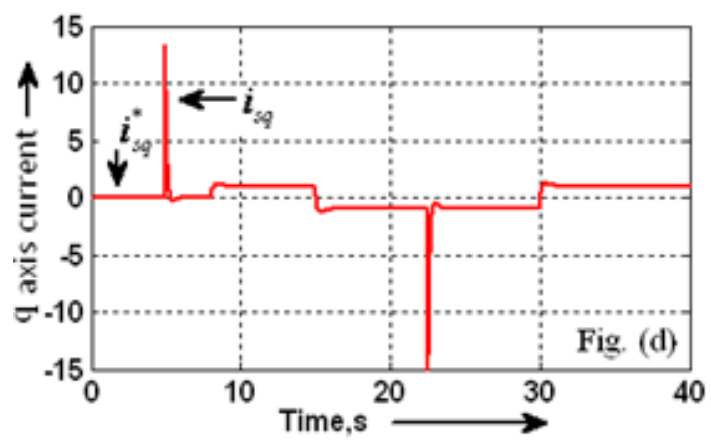

(d)

Figure 8. Simulation results in motoring and regenerating mode (a) reference and actual rotor speed (b) rotor flux (c) d axis current (d) q axis current

\section{EXPERIMENTAL SET-UP}

This section deals with the development of laboratory based prototype to test the proposed algorithms. The test set-up is built with the help of a dSPACE-1104. The block diagram of the complete setup is presented in Figure 9, which comprises of the following subsystems. Also, the hardware set-up is presented in Figure 10.

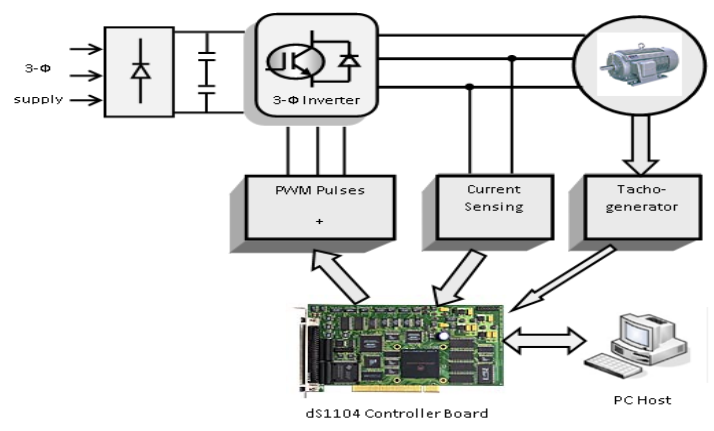

Figure 9. Block diagram of the experimental system

\subsection{Control Unit}

The control unit operates through dSPACE-1104 controller board. The current is sensed and scaled before feeding to the controller. In case of any fault, the system has debugging facility through a fault indication system. Control unit has the following functional blocks.

- dSPACE-1104 controller board 
Sensing of phase current

PWM processing block

- Protection and fault indication block

\subsection{Power Unit}

- Three phase rectifier

- Voltage source inverter

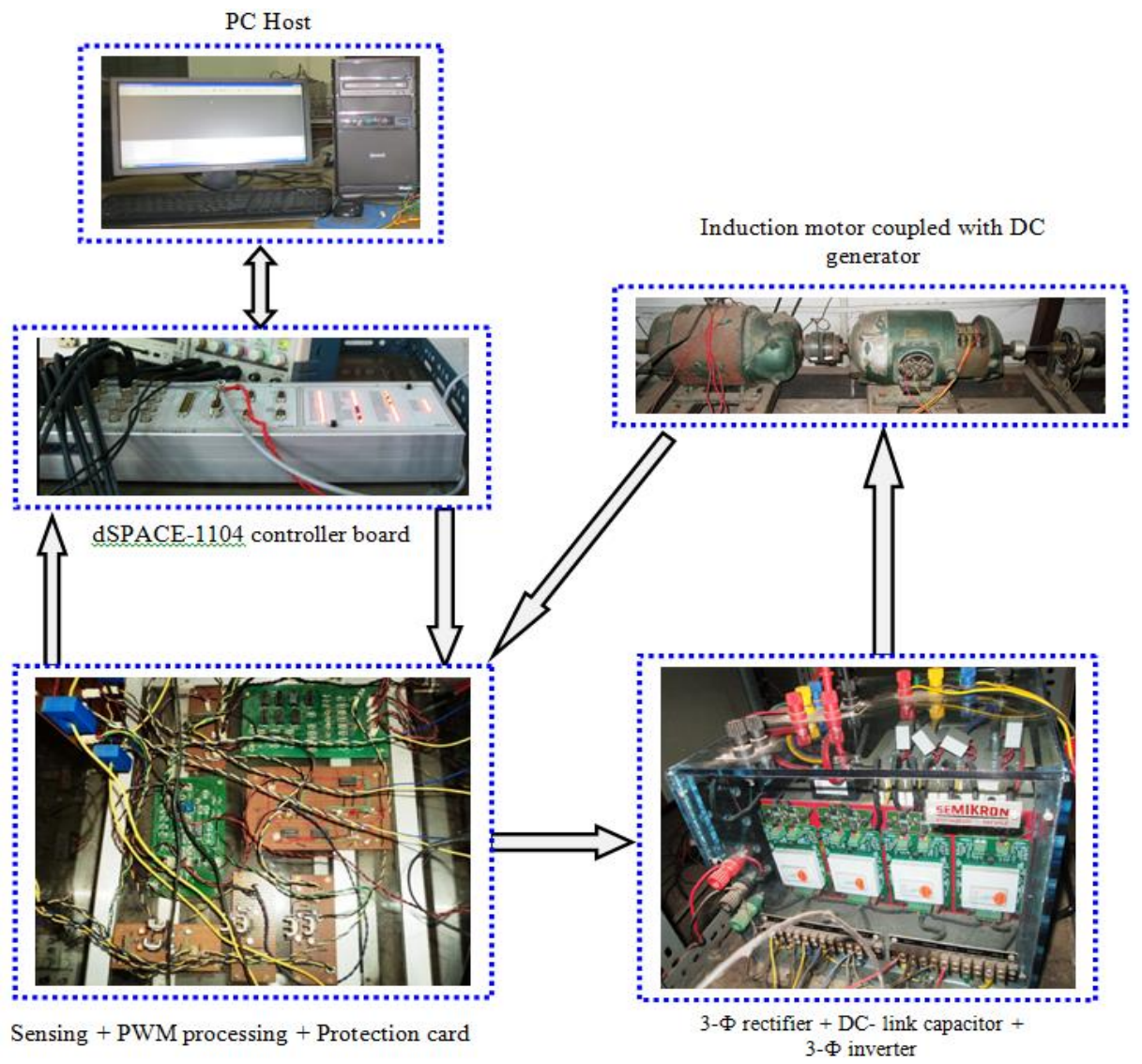

Figure 10. Laboratory developed hardware prototype

\section{EXPERIMENTAL RESULTS}

The proposed current sensorless algorithm is tested in hardware using dSPACE-1104 based laboratory prototype. Some of the experimental results are presented, corresponding to the simulation results of previous section. The experiments are performed through a laboratory developed prototype, built around a dSPACE-1104 controller board.

\subsection{Step change in rotor speed}

The response for step change in rotor speed can be seen in Figure 11. A step change in speed of 20 $\mathrm{rad} / \mathrm{s}$ is applied at $4.35 \mathrm{~s}$ from $0 \mathrm{rad} / \mathrm{s}$. The reference and actual rotor speeds are available in Figure 11(a). Flux orientation is well maintained as shown in Figure 11(b). The d- and q-axis components of stator currents are shown in Figure 11(c) and Figure 11(d). The actual and estimated $\alpha$ - and $\beta$-axis currents are presented in Figure 11(e) and Figure 11(f). It is observed that estimated current follows the actual with negligible error.

\subsection{Speed Reversal}

The performance of the system under speed reversal is presented in Figure 12. The reference vs actual rotor speeds is shown in Figure 12(a). Experimental results show good dynamics during speed reversal. The flux is oriented as seen in Figure 12(b). The $\mathrm{d}$ and $\mathrm{q}$ axis stator currents are shown in Figure 12(c) and Figure 12(d). Performance of the current estimator is presented in Figure 12(e) and Figure 12(f), which reveals the error between actual and estimated current is negligibly small. 


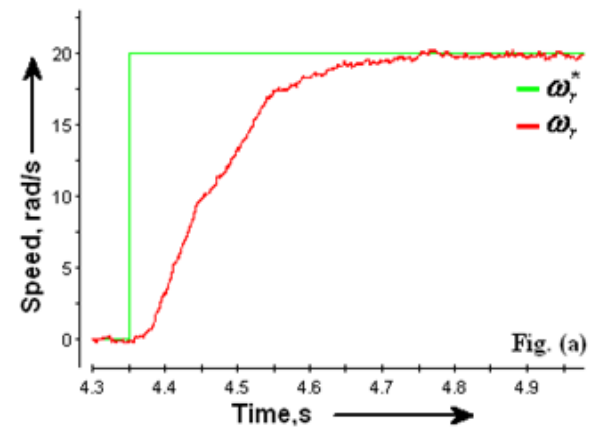

(a)

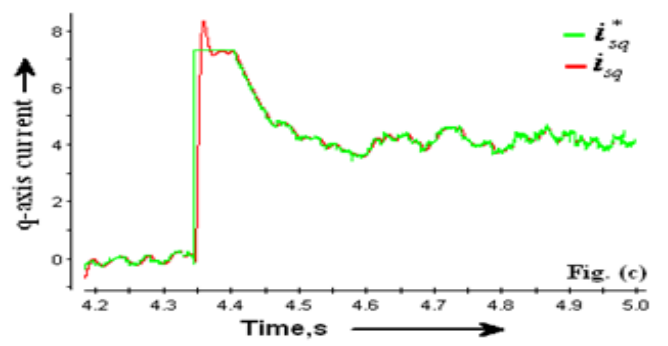

(c)

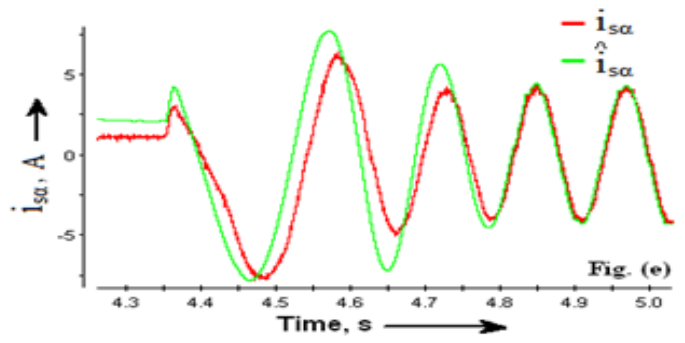

(e)

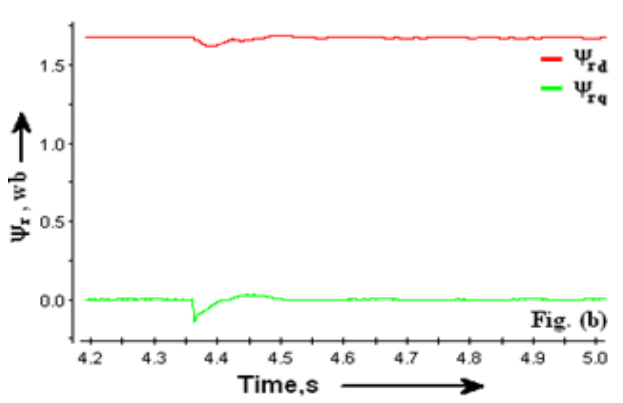

(b)

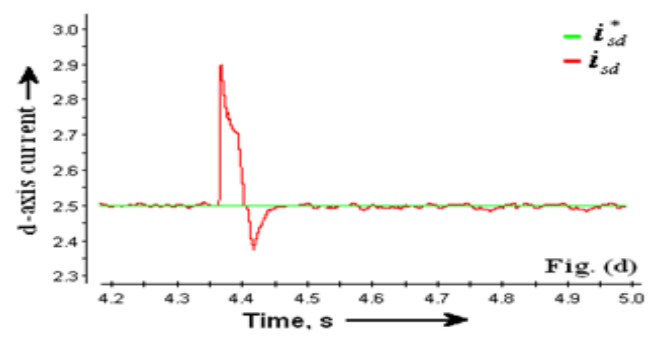

(d)

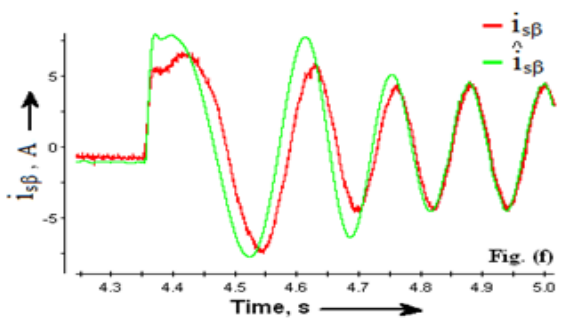

(f)

Figure 11. Experimental results under step change in speed $\left(\mathrm{T}_{\mathrm{L}}=0.5 \mathrm{pu}\right)$ (a) reference and actual rotor speed (b) rotor flux (c) q-axis current (d) d-axis current (e) $\alpha$-axis current (f) $\beta$-axis current

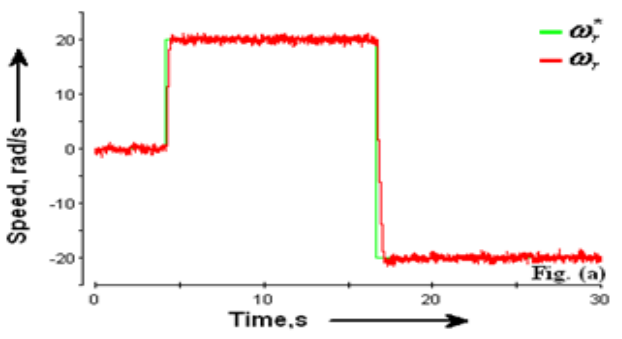

(a)

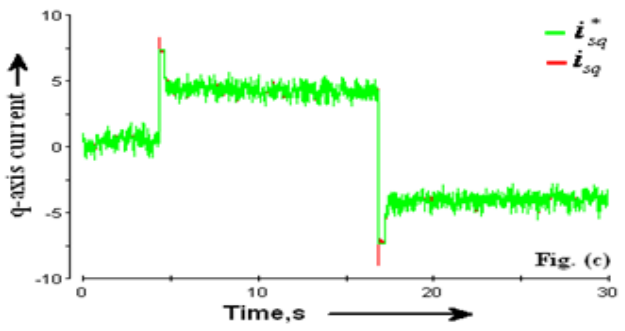

(c)

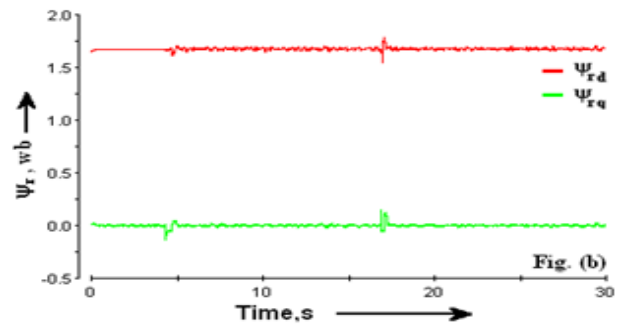

(b)

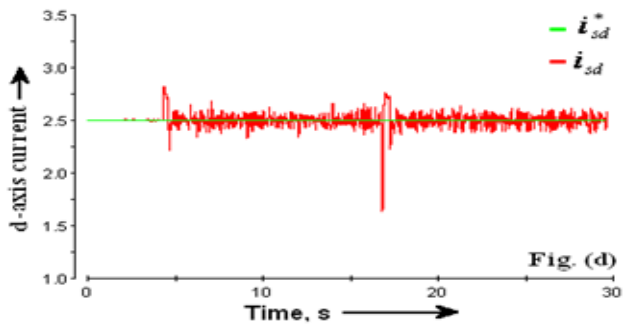

(d)

Figure 12. Experimental results under speed reversal $\left(\mathrm{T}_{\mathrm{L}}=0.5 \mathrm{pu}\right)$ (a) reference and actual rotor speed (b) rotor flux (c) q-axis current (d) d-axis current 


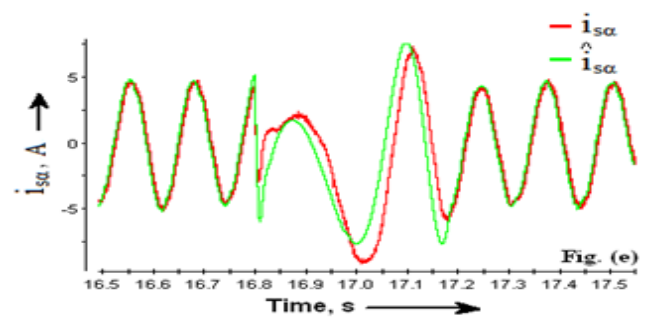

(e)

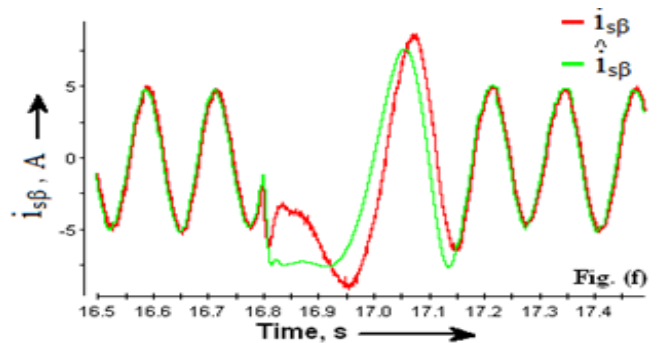

(f)

Figure 12. Experimental results under speed reversal $\left(T_{L}=0.5 p u\right)(e) \alpha$-axis current (f) $\beta$-axis current

\subsection{Ramp Response}

The performance of drive under slow zero crossing is observed when reference speed is changed from positive to negative in the form of a ramp. The reference and actual speed, rotor flux component, flux and torque component of stator current, actual and estimated values of $\alpha$ - and $\beta$-axis current are presented in Figure 13.

\subsection{Performance under sinusoidal speed command}

The performance of the sensorless drive under sinusoidal speed command is observed in Figure 14. Reference versus actual speed is shown in Figure 14(a). It is observed that the actual speed tracks the reference one with good accuracy. From Figure 14(b), it is noticed that flux orientation is maintained throughout the operation. The flux and torque components of currents are shown in Figure 14(c) and Figure 14(d).

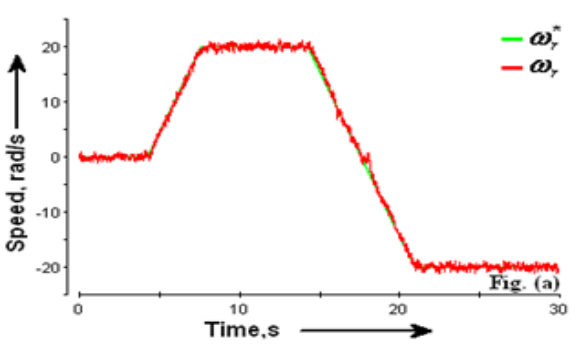

(a)

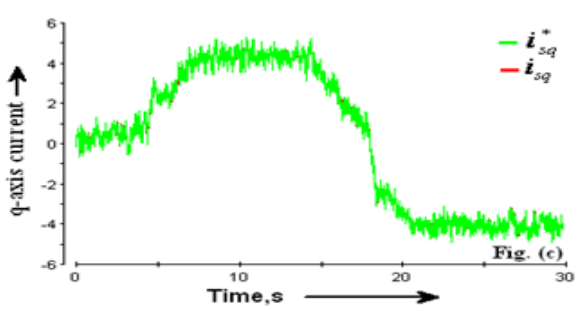

(c)

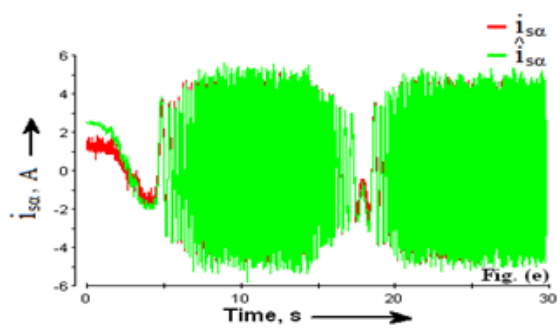

(e)

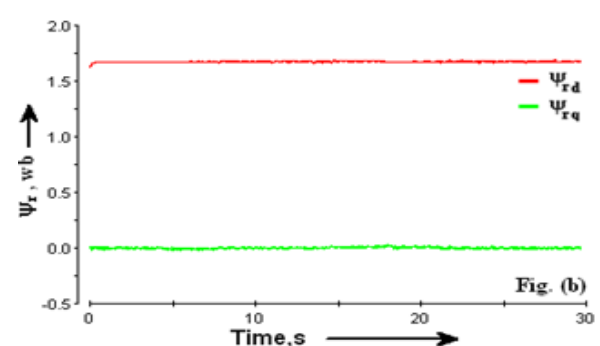

(b)

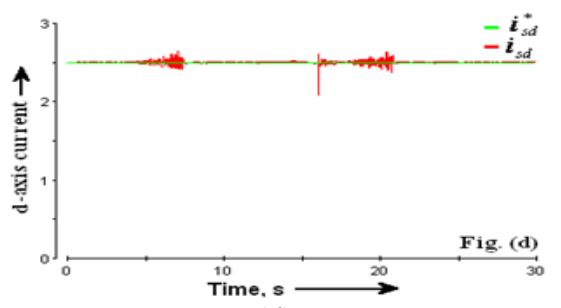

(d)

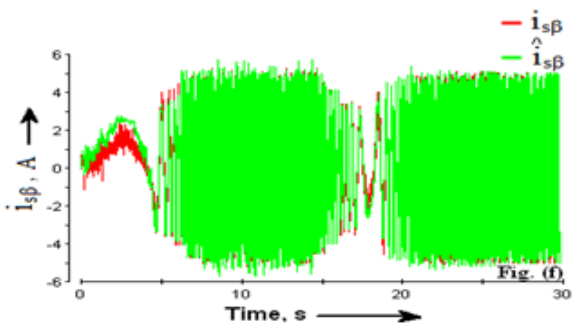

(f)

Figure 13. Experimental results under ramp speed command $\left(T_{L}=0.5 p u\right)$ (a) reference and actual rotor speed (b) rotor flux (c) q-axis current (d) d-axis current (e) $\alpha$-axis current (f) $\beta$-axis current 


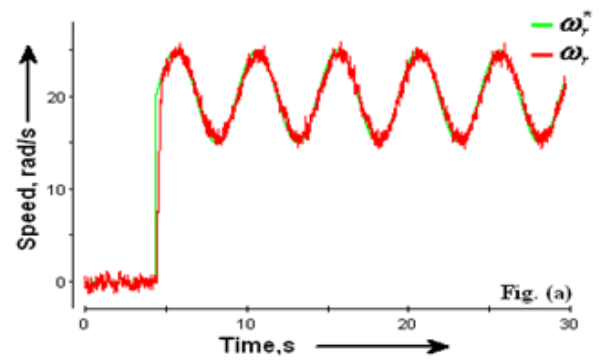

(a)

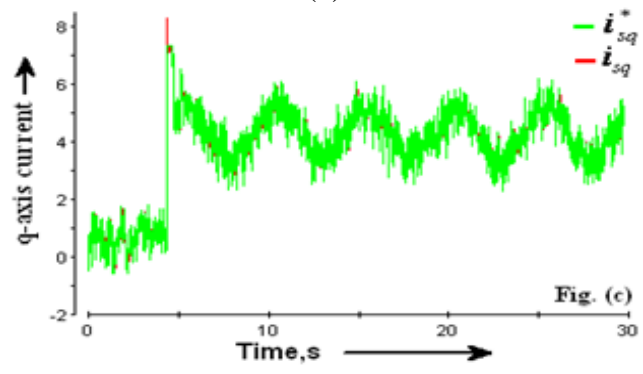

(c)

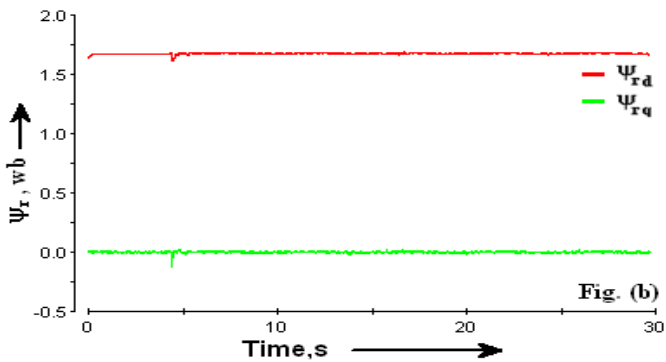

(b)

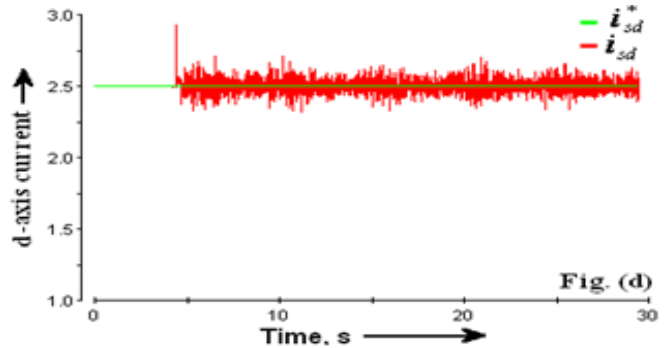

(d)

Figure 14. Experimental results under sinusoidal speed command $\left(\mathrm{T}_{\mathrm{L}}=0.5 \mathrm{pu}\right)$ (a) reference and actual rotor speed (b) rotor flux (c) q-axis current (d) d-axis current

\subsection{Performance under triangular speed command}

The performance of drive under triangular speed command is observed in Figure 15. It is observed that the actual speed tracks the reference one with good accuracy as shown in Figure 15(a). From Figure 15(b), it is noticed that flux orientation is maintained throughout the operation. The d- and qaxis stator currents are presented in Figure 15(c) and Figure 15(d).

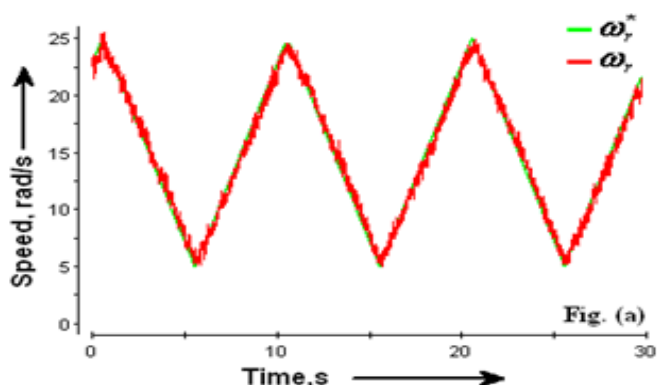

(a)

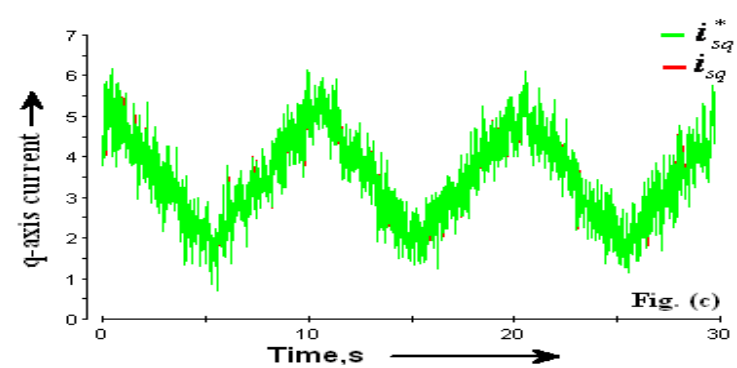

(c)

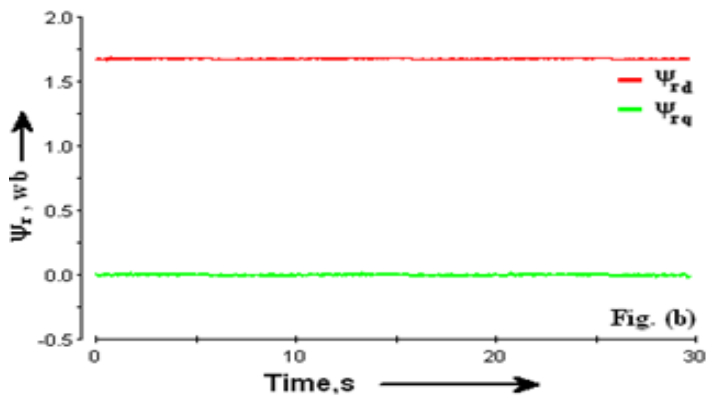

(b)

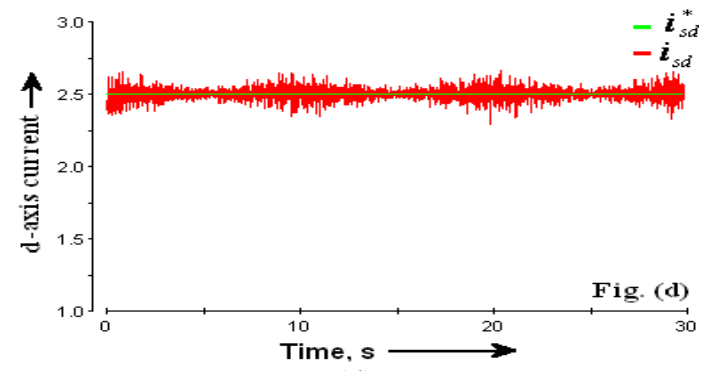

(d)

Figure 15. Experimental results triangular speed command (TL=0.5pu) (c) q-axis current $(\mathrm{d}) \mathrm{d}$-axis current 


\subsection{Operation at zero speed for short duration}

Performance of the drive under zero speed operation for short duration is studied by applying a pulse type speed command. Figure 16 presents the results under such operating conditions. Satisfactory performance of the drive is obtained. The actual speed, rotor flux, flux and torque component of stator currents are presented in the figure sequentially. Decoupling is observed between flux and torque producing components of stator current. The load is modeled like a DC generator, which offers zero load torque at standstill. So, the torque component of the stator current (i.e. $i_{s q}$ ) is very small at zero speed, as shown in Figure 16(c).

\subsection{Performance of the drive under persistent zero speed operation}

Performance of the drive under continuous zero speed operation is presented in Figure 17. The motor speed is brought down to zero from $+20 \mathrm{rad} / \mathrm{s}$ at $4.3 \mathrm{~s}$ in the form of a step. The reference and actual rotor speed are shown in Figure 17(a). The rotor flux components in rotating reference frame is presented in Figure 17(b). It is observed that orientation of flux is maintained even at zero speed. Also, decoupling is observed between flux and torque producing components of the stator current. Here load is modeled like a DC generator, which offers zero load torque at standstill. Thus, the torque component of stator current (i.e. $i_{s q}$ ) is very small at zero speed, as shown in Figure 17(c). The flux component of stator current (i.e. $i_{s d}$ ) is presented in Figure 17(d).

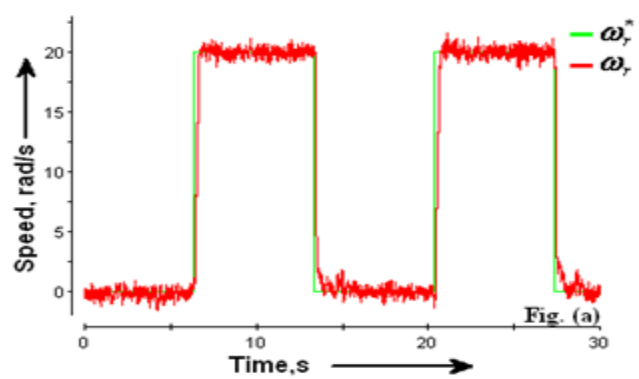

(a)

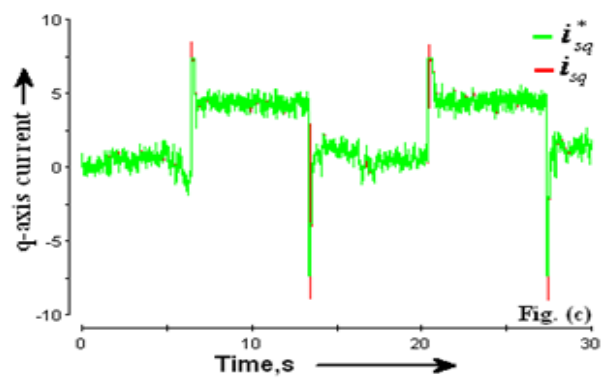

(c)

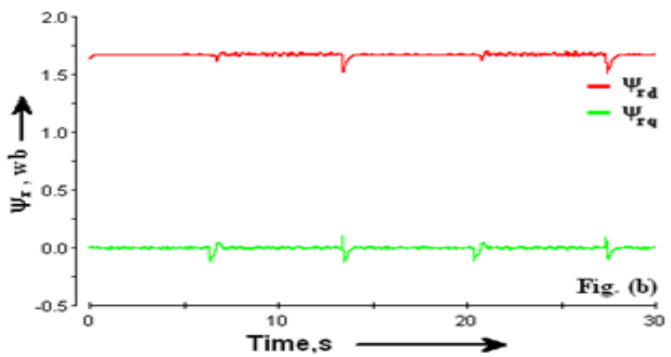

(b)

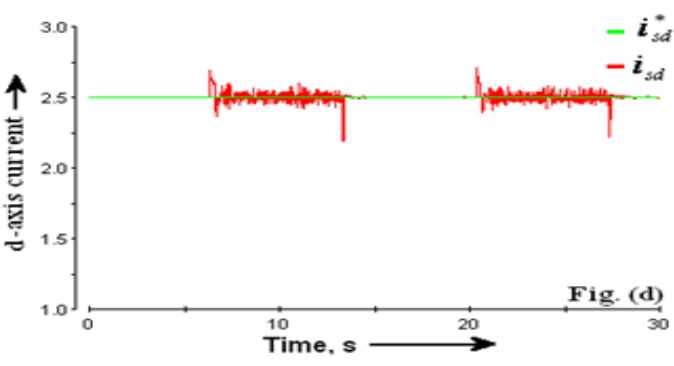

(d)

Figure 16. Experimental results under zero speed operation for short duration (a) reference and actual rotor speed (b) rotor flux (c) q-axis current (d) d-axis current

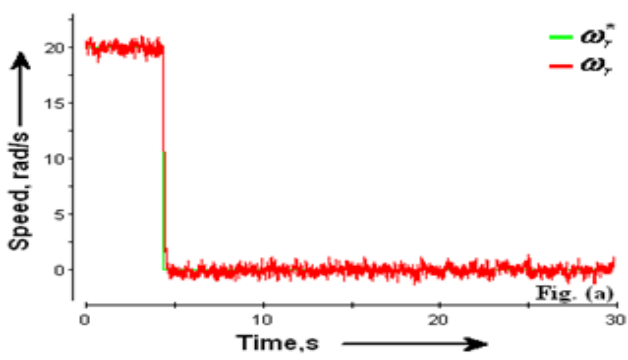

(a)

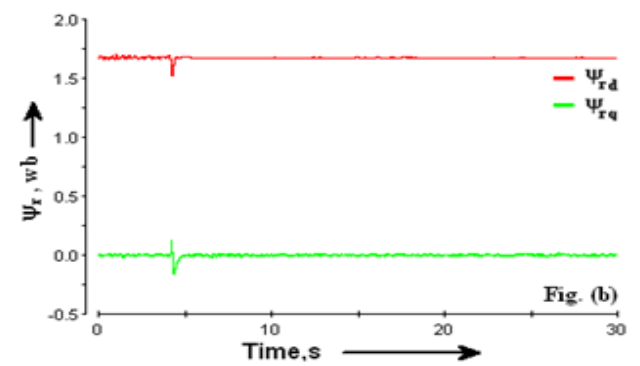

(b)

Figure 17. Experimental results for persistent zero speed (a) reference and actual rotor speed (b) rotor flux 


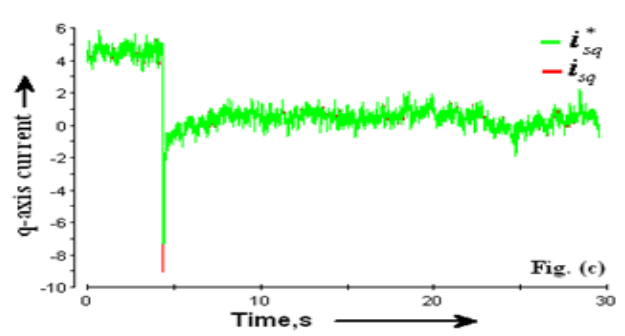

(c)

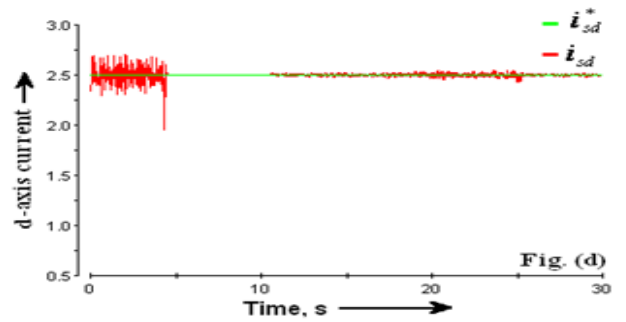

(d)

Figure 17. Experimental results for persistent zero speed (c) q-axis current (d) d-axis current

\section{CONCLUSIONS}

This paper proposes a new current sensorless system for vector controlled induction motor drive based on current estimation in two phase stationary reference frame. The sensor used in the proposed system is only a speed sensor/encoder. The proposed current estimation algorithm is simple and economical. Proposed technique is quite useful for the applications where speed/position sensor is available. In case of volt/Hertz drive, where speed sensor is present, vector control can be achieved with the help of proposed algorithm. Proposed method can also be used in applications where speed/position sensor cannot be eliminated to assure accuracy and reliability. Proposed method estimates the currents in two phase stationary reference frame with the help of simple equations. Proposed algorithm has been simulated in MATLAB/SIMULINK and experimentally verified with the laboratory prototype. The prototype is built with dSPACE 1104. A good dynamic and steady state performance of the drive is observed.

\section{REFERENCES}

[1] T. C. Green and B. W. Williams, "Derivation of motor line-current waveforms from the DC-link current of an inverter,” Proc. Inst. Elect. Eng.,vol. 136, no. 4, pp. 196-204, July 1989.

[2] J. F. Moynihan, S. Bolognani, R. C. Kavanagh, M. G. Egan, and J. M. D. Murphy, "Single sensor current control of AC servo drives using digital signal processors," in Proc. 5th Eur. Conf. Power Electron. Appl.. Brighton, MA, vol. 4, pp. 415-421, Sep. 1993.

[3] M. Riese, "Phase current reconstruction of a three-phase voltage source inverter fed drive using a sensor in the DC-link," Proc. Power Convers. Intell. Motion Conf., pp. 95-101, 1996.

[4] T. M. Wolbank and P. E. Macheiner, "An improved observer-based current controller for inverter fed AC machines with single DC-link current measurement," in Proc. IEEE Power Electron. Specialists Conf., Cairns, Australia, Jun. 23-27, pp. 1562-1567, 2002.

[5] T. M. Wolbank and P. Macheiner, "Scheme to reconstruct phase current information of inverter fed AC drives," IEE Electron. Lett., vol. 38, no. 5,pp. 204-205, Feb. 2002.

[6] F. Blaabjerg and J. K. Pedersen, "An ideal PWM-VSI inverter using only one current sensor in the DC-link," in Proc. 5th Int. Power Electronics and Variable-Speed Drives Conf., pp. 458-464, 1994.

[7] W. C. Lee, T. K. Lee, and D. S. Hyun, "Comparison of single-sensor current control in the DC-link for three-phase voltage-source PWM converters," IEEE Trans. Ind. Electron., vol. 48, no. 3, pp. 491-505, June 2001.

[8] D. C. Lee and G. M. Lee, "A novel overmodulation technique for space-vector PWM inverters," IEEE Trans. Power Electron., vol. 13, no. 6, pp.1144-1151, Nov.1998.

[9] M.O. Sonnaillon, G. Bisheimer, C. De Angelo, J. Solsona, and G.O. Garcia, "Mechanical-sensorless induction motor drive based only on DC-link measurements," IEE Proc. of Electric Pow. Applicat., vol. 153, no. 6, pp. 815-822, Nov. 2006.

[10] M. Bertoluzzo, G. Buja, and R. Menis, "Direct torque control of an induction motor using a single current sensor," IEEE Trans. Ind. Electron., vol. 53, no. 3, pp. 778-784, June 2006.

[11] F. Blaabjerg and J. K. Pedersen, "A new low cost, fully fault-protected PWM-VSI inverter with true phase-current information,” IEEE Trans. Power Electron., vol. 12, no. 1, pp.187-197, Jan.1997.

[12] S.N. Vukosavic and A. M. Stankovic, "Sensorless Induction motor drive with a single DC-link current sensor and instantaneous active and reactive power feedback," IEEE Trans. Ind. Electron., vol. 48, no. 1, pp. 195-204, Feb. 2001.

[13] T. M. Wolbank and P. E. Macheiner, "Current-controller with single DC-link current measurement for inverter-fed ac machines based on an improved observer-structure," IEEE Trans. Power Electron., vol. 19, no. 6, pp. 1562-1567, Nov. 2004.

[14] M. Montanari, S. Peresada, C. Rossi and A. Tilli, "Current sensorless position-flux tracking controller for induction motor drives," J. Mechatron., vol. 17, pp. 15-30, 2007.

[15] B. Singh and D. Goyal, "Improved DSVM-DTC based current sensorless permanent magnet synchronous motor drive,” in Proc. Int. Conf. Power Electron. Drive Syst., pp. 1354-1360, 2007. 
[16] S. Morimoto, M. Sanada and Y. Takeda, "High-performance current sensorless drive for synchronous motors with only low-resolution position sensor," in Proc. Conf. Rec. IAS Annu. Meet., pp. 2065-2072, vol. 2063, 2002.

[17] T. Matsuo and T. A. Lipo, "Current sensorless field oriented control of synchronous reluctance motor," in Proc. Conf. Rec. IAS Annu. Meet., pp. 672-678, vol. 671, 1993.

[18] A. Consoli, G. Scarcella and A. Testa, "Speed and current sensorless field oriented induction motor drive operating at low stator frequencies," in Proc. Conf. Rec. IAS Annu. Meet., pp. 1679-1686, vol. 1673, 2002.

[19] S. C. Chang and S. N. Yeh, "Current sensorless field-oriented control of induction motors," IEE Proc. Electr. Power Appl., vol. 143, pp. 492-500, 1996.

[20] H. Wang, S. Pekarek and B. Fahimi, "Elimination of position and current sensors in high performance adjustable speed ac drives," in Proc. Conf. Electrical Machines and Drives, pp. 1902-1911, 2005.

[21] K. Ohishi and K. Yoshida, "Current sensor-less speed servo system of PM motor based om self-tuning current simulator," in Proc. Conf. Electrical Machines and Drives, pp. 1895-1900, 2003.

[22] S. Morimoto, M. Sanada and Y. Takeda, "Optimum efficiency operation of synchronous reluctance motor without current sensor," in Proc. Conf. Power Electronics and Variable Speed Drives, 18-19 September, pp. 506-511, 2000.

[23] Y. S. Lai, Y. K. Lin, and C. W. Chen, "New hybrid pulsewidth modulation technique to reduce current distortion and extend current reconstruction range for a three-phase inverter using only dc-link sensor," IEEE Trans. Power. Electron., vol. 28, no. 3, pp. 1331-1337, Mar. 2013.

[24] H. Lu, X. Cheng, W. Qu, S. Sheng, Y. Li, and Z. Wang, "A three-phase current reconstruction technique using single dc current sensor based on TSPWM," IEEE Trans. Power. Electron., vol. 29, no. 3, pp. 1542-1550, Mar. 2014.

[25] Y. Cho, B. J. Byen, and G. H. Choe, "Multi-branch current sensing technique for three-phase reconstruction with non-contact-type current sensor," IEEE Electronics Letter, vol. 50, no. 5, pp. 391-393, Feb. 2014.

[26] B. Metidji, N. Taib, L. Baghil, T. Rekioua, and S. Bacha, "Novel single current sensor topology for venturini controlled direct matrix converters," IEEE Trans. Power. Electron., vol. 28, no. 7, pp. 3509-3516, July 2013.

[27] B. Metidji, N. Taib, L. Baghil, T. Rekioua, and S. Bacha, "Phase current reconstruction using a single current sensor of three-phase ac motors fed by SVM-controlled direct matrix converters," IEEE Trans. on Ind. Electron., vol. 60, no. 12, pp. 5497-5505, Dec. 2013.

\section{APPENDIX}

Table 1. Induction Machine Rating and Parameters

\begin{tabular}{lc}
\hline Stator phase voltage $(\mathrm{V})$ & 400 \\
Shaft power $(\mathrm{kW})$ & 1.8 \\
Pole pairs & 2 \\
Base speed $(\mathrm{rpm})$ & 1370 \\
Magnetizing inductance $(\mathrm{mH})$ & 670.5 \\
Stator and rotor leakage inductance $(\mathrm{mH})$ & 14.3 \\
Stator resistance $(\Omega)$ & 5.71 \\
Rotor resistance $(\Omega)$ & 4.08 \\
Rotor inertia $\left(\mathrm{Kg}-\mathrm{m}^{2}\right)$ & 0.011 \\
\hline
\end{tabular}

List of symbols

$v_{s d}, v_{s q} \quad \mathrm{~d}$ and q components of the stator voltage vector

$v_{s \alpha}, v_{s \beta} \quad \alpha$ and $\beta$ components of the stator voltage vector

$i_{s d}, i_{s q} \quad \mathrm{~d}$ and q components of the stator current vector

$i_{s \alpha}, i_{s \beta} \quad \alpha$ and $\beta$ components of the stator current vector

$\psi_{r d}, \psi_{r q} \mathrm{~d}$ and q components of the rotor flux vector

$\omega_{s l} \quad$ Slip speed

$\omega_{r} \quad$ Actual rotor speed

$\rho_{m s} \quad$ Position of rotor flux vector

* Denotes reference quantities

$\wedge \quad$ Denotes estimated quantities 